\title{
Safety and Efficacy of Short-Term Intrapulmonary Percussive Ventilation in Patients With Bronchiectasis
}

\author{
Mara Paneroni RTD, Enrico Clini MD, Carla Simonelli RTD, Luca Bianchi MD, \\ Francesca Degli Antoni RTD, and Michele Vitacca MD
}

\begin{abstract}
BACKGROUND: Treatment of bronchiectasis includes drugs, oxygen therapy, and bronchialclearance maneuvers. OBJECTIVE: To assess the safety and efficacy of intrapulmonary percussive ventilation (IPV) compared to traditional standard chest physical therapy in patients with bronchiectasis and productive cough. METHODS: In a randomized crossover study, 22 patients underwent, on consecutive days, IPV and chest physical therapy. Before each treatment session, immediately after the session, 30 min after the session, and 4 hours after the session we measured $\mathrm{S}_{\mathrm{pO}_{2}}$, heart rate, respiratory rate, and (with a visual analog scale) the patient's subjective sensation of phlegm encumbrance and dyspnea. Immediately after each treatment session we also measured (via visual analog scale) the patient's discomfort. We also measured the volume and wet and dry weight of collected sputum. RESULTS: No adverse effects were so severe as to require discontinuation of treatment, and the incidence of adverse effects was similar in the groups $(27 \%)$. Heart rate $(P=.002)$ and respiratory rate $(P=.047)$ decreased during treatment, and sensation of phlegm encumbrance improved $(P=.03)$ with both treatments. Only IPV improved $(P=.004)$ the sensation of dyspnea. The patients found IPV more comfortable than our traditional standard chest physical therapy $(P=.03)$. Both treatments caused important phlegm production, but there were no differences in sputum volume, wet weight, or dry weight. CONCLUSIONS: In patients with bronchiectasis and productive cough, short-term IPV was as safe and effective as traditional chest physical therapy, with less discomfort. Key words: bronchiectasis; intrapulmonary percussive ventilation; chest physical therapy; rehabilitation; hypersecretion; airway and pulmonary infections. [Respir Care 2011;56(7):984988. (C) 2011 Daedalus Enterprises]
\end{abstract}

\section{Introduction}

Proper functioning of bronchial clearance relies on balance between mucus production, transport, and clearance. ${ }^{1}$ Impairment of this balance can result in phlegm encumbrance, together with changes in physiological clearance mechanisms. ${ }^{1}$ This can favor recurrent infections, affect ventilatory function, and create a vicious circle of infec-

Drs Paneroni, Simonelli, Bianchi, and Vitacca are affiliated with Servizio di Riabilitazione Cardio-Respiratoria, Salvatore Maugeri Foundation, Istituto di Ricovero e Cura a Carattere Scientifico, Institute of Lumezzane, Lumezzane, Italy. Drs Clini and Degli Antoni are affiliated with the University of Modena, and with L'unità Operativa di Pneumologia e Riabilitazione Respiratoria, Ospedale Privato Accreditato Villa Pineta, Gaiato, Italy.

This research was partly supported by MedicAir Italia. The authors have disclosed no other conflicts of interest. tions and inflammation that can ultimately lead to airway and lung parenchyma destruction. ${ }^{1}$

Bronchiectasis, a disease that is being diagnosed with increasing frequency, ${ }^{2}$ consists of segmental dilatation of medium-size bronchi, due to loss of the muscle and elastic components of the bronchial wall in patients without cystic fibrosis $(\mathrm{CF})$. Bronchiectasis is usually associated with chronic cough, increasing secretions, and recurrent airway and pulmonary infections that might result in loss of lung function and lead to early death. ${ }^{2}$ The goals of bronchiec-

\footnotetext{
Correspondence: Mara Paneroni RTD, Respiratory Department, Salvatore Maugeri Foundation, Istituto di Ricovero e Cura a Carattere Scientifico, Institute of Lumezzane, Lumezzane, Italy. E-mail: mara.paneroni@ fsm.it.
}

DOI: $10.4187 /$ respcare.01098 


\section{Short-Term Intrapulmonary Percussive Ventilation in Patients With Bronchiectasis}

tasis treatment are to reduce the number of exacerbations and infections and to improve patient quality of life by reducing airway inflammation and mobilizing secretions. ${ }^{3,4}$

Depending on the degree of lung function impairment, accepted standard treatment includes drugs, oxygen therapy, and daily bronchial-clearance maneuvers. ${ }^{3}$ Proposed secretion management techniques include standard $^{5}$ and modified ${ }^{1,5}$ postural drainage, assisted cough, ${ }^{5}$ active cycle of breathing techniques, ${ }^{5,6}$ autogenic drainage, ${ }^{5}$ inspiratory muscle endurance training, ${ }^{6}$ oscillatory positive-expiratory-pressure devices (eg, Flutter ${ }^{5}$ and Acapella ${ }^{6}$ ), and intrapulmonary percussive ventilation (IPV). Although the treatment of mucus hypersecretion is recommended in chronic respiratory diseases, ${ }^{1}$ there have been no definitive studies or guidelines on preference of one clearance technique versus the others. ${ }^{7}$

IPV is powered with a pressure of about $50 \mathrm{~cm} \mathrm{H}_{2} \mathrm{O}$ and delivers small bursts of high-flow gas at 100-300 cycles/ min, ${ }^{8}$ which causes airway pressure changes of 5-35 cm $\mathrm{H}_{2} \mathrm{O}$, and vibrates the airway walls. IPV improves airway secretion clearance in CF patients, ${ }^{9,10}$ Duchenne muscular dystrophy, ${ }^{11}$ pediatric patients with atelectasis, ${ }^{12}$ COPD exacerbation, ${ }^{13,14}$ obesity, ${ }^{15}$ tracheostomized patients ${ }^{16}$ and patients with acute respiratory failure. ${ }^{13}$ To our knowledge there have been no trials of IPV in patients with bronchiectasis. We compared the safety, comfort, and efficacy of IPV and our standard traditional chest physical therapy (CPT) method in airway secretion clearance in adult patients with bronchiectasis.

\section{Methods}

This study was approved by the ethic committees of both Fondazione Maugeri Istituto di Ricovero e Cura a Carattere Scientifico, Lumezzane, Italy, and Ospedale Privato Accreditato Villa Pineta, Gaiato, Italy. All patients gave written informed consent.

\section{Patients}

We screened all consecutive patients admitted to the respiratory departments of our 2 institutions, from September 2005 to March 2008. The inclusion criteria were:

- Diagnosis of bronchiectasis based on computed tomogram

- Daily sputum volume $>20 \mathrm{~mL}$ for at least 2 consecutive days

- Clinical stability: no need for medication changes 4 days prior to enrollment

- Normal gas exchange: $\mathrm{pH}>7.35$ during spontaneous breathing, with or without supplemental oxygen

- No use of sedatives or vasopressors

- No major cardiac arrhythmias or hemodynamic instability (eg, severe hypotension, sepsis, or low cardiac output)

The exclusion criteria were tracheostomy, long-term noninvasive ventilation (NIV), severe and/or irreversible sensory abnormalities, and chest radiograph changes.

The drop-out criteria were withdrawal of patient consent, severe clinical worsening, and occurrence of any of the exclusion criteria.

\section{Protocol}

We used a randomized crossover design. On 2 consecutive days, each patient performed one of the secretion clearance techniques on the first day and the other technique on the second day, per a computerized randomization list. Both secretion clearance sessions were $30 \mathrm{~min}$ utes long. If the patient was on supplemental oxygen, the oxygen flow was maintained constant during both treatments.

\section{Intrapulmonary Percussive Ventilation}

IPV was provided with the IMP2 (Breas Medical, Mölnlycke, Sweden). Each IPV session included 3 active cycles, including 2 phases at low pressure and high frequency, and another phase at high pressure and low frequency. The patient was in a sitting position. At the end of each cycle the respiratory therapist required the patient to cough. The session was performed without delivery aerosol therapy.

\section{Chest Physical Therapy}

CPT consisted of a combination of forced expiration, postural drainage, percussion, and vibration. ${ }^{17,18}$ Each of 3 positions (prone, right-lateral decubitus, and left-lateral decubitus) was maintained for $10 \mathrm{~min}$, and after each position the patient sat upright for $3 \mathrm{~min}$ of coughing.

\section{Measurements}

At baseline we recorded demographics, anthropometry, respiratory function, $\mathrm{P}_{\mathrm{aO}_{2}}, \mathrm{P}_{\mathrm{aCO}_{2}}$, and $\mathrm{pH}$. Before each treatment session (time zero [T0]), immediately after the session (T1), 30 min after the session (T2), and 4 hours after the session (T3) we measured $\mathrm{S}_{\mathrm{pO}_{2}}$, heart rate, respiratory rate, and (with a visual analog scale ${ }^{19}$ ) the patient's subjective sensation of phlegm encumbrance and dyspnea. At T1 we also measured the patient's subjective discomfort 


\section{Short-Term Intrapulmonary Percussive Ventilation in Patients With Bronchiectasis}

Table 1. Baseline Characteristics $(n=22)$

\begin{tabular}{|c|c|}
\hline Male/female, no. & $12 / 10$ \\
\hline Age $(y)$ & $64.4 \pm 8.9$ \\
\hline $\mathrm{FEV}_{1}(\%$ predicted $)$ & $53 \pm 30$ \\
\hline FVC $(\%$ predicted $)$ & $69 \pm 21$ \\
\hline $\mathrm{P}_{\operatorname{Imax}}(\%$ predicted $)$ & $48 \pm 29$ \\
\hline $\mathrm{P}_{\text {Emax }}(\%$ predicted $)$ & $50 \pm 22$ \\
\hline $\mathrm{pH}$ & $7.41 \pm 0.03$ \\
\hline $\mathrm{P}_{\mathrm{aO}_{2}}(\mathrm{~mm} \mathrm{Hg})$ & $66 \pm 10$ \\
\hline $\mathrm{P}_{\mathrm{aCO}_{2}}(\mathrm{~mm} \mathrm{Hg})$ & $47 \pm 10$ \\
\hline \multicolumn{2}{|l|}{$\begin{array}{l} \pm \text { values are mean } \pm \text { SD. } \\
\text { FVC }=\text { forced vital capacity }\end{array}$} \\
\hline $\begin{aligned} \mathrm{FVC} & =\text { forced vital capacity } \\
& =\text { maximum }\end{aligned}$ & \\
\hline $\mathrm{P}_{\mathrm{Emax}}=$ maximum expiratory pressure & \\
\hline
\end{tabular}

with a $0-100 \%$ discomfort visual analog scale. ${ }^{20} \mathrm{We}$ also measured the volume and wet and dry weight of collected sputum. We asked the patients about adverse effects throughout the 30-min treatment session and at $\mathrm{T} 3$.

\section{Statistical Analysis}

Statistical assumption for paired $t$ test power calculation was made on the efficacy. On the grounds of our previous experience we estimated an $80 \%$ power to detect a reduction of 6 points in the average value of the efficacy proportion between the 2 treatments. Differences were considered significant when $P<.05$. The estimated number of patients to be enrolled was 22. Data analysis was with statistics software (SPSS 12.0, SPSS, Chicago, Illinois).

Though we randomized the order of treatments, we could not rule out the possibility that the order of treatment or a learning effect might affect our results, so we divided the patients into 2 groups according to random order: IPV first, and CPT first. We tested for a "period effect" for each variable with a 2-sample $t$ test (or Mann-Whitney U test for nonparametric variables) to compare the differences between the treatment periods in the latter 2 groups. We tested for a "treatment-period interaction" with a 2-sample $t$ test that compared the average of response to treatment in each group. If a period effect or treatment-period effect for each variable was found to be statistically nonsignificant, then we calculated the differences between the 2 treatments with the Student $t$ test (paired data) or the Wilcoxon test (nonparametric data).

\section{Results}

\section{Patients}

There were 1,920 patients admitted during the study period. We screened 32 patients and enrolled 12 men and 10 women (Table 1). Reasons for exclusion were: unstable
Table 2. Mean Differences Between Intrapulmonary Percussive Ventilation and Standard Chest Physical Therapy

\begin{tabular}{lccl}
\hline \hline & $\begin{array}{c}\text { Mean } \\
\text { Difference }\end{array}$ & 95\% CI & $P$ \\
\hline Sputum & & & \\
$\quad$ Volume (mL) & -0.68 & -3.80 to 2.43 & .65 \\
Wet weight (g) & 3.00 & -8.48 to 14.48 & .58 \\
Dry weight (g) & -0.31 & -0.87 to 0.26 & .26 \\
$\Delta$ Respiratory rate (breaths/min) & -1.6 & -3.2 to -0.02 & .047 \\
$\Delta$ Heart rate (beats/min) & -0.4 & -3.6 to 2.9 & .82 \\
$\Delta \mathrm{S}_{\mathrm{pO}_{2}}(\%)$ & 0.6 & -0.7 to 2.0 & .35 \\
\hline
\end{tabular}

disease ( 4 patients), tracheotomy (1 patient), NIV (2 patients), and refusal ( 3 patients). All the patients completed both airway clearance sessions. All the patients were clinically stable, and had moderate hypoxemia, mild hypercapnia, obstructive pattern, and reduced respiratory muscle function, but were able to cough spontaneously.

\section{Response to Treatment}

Table 2 shows the mean differences between IPV and standard CPT in collected sputum and change in respiratory rate, heart rate (beats/min), and $\mathrm{S}_{\mathrm{pO}_{2}}$. IPV or CPT were similarly safe in all the patients, as demonstrated by stability or mild improvement in physiological response during their application. In detail:

- $\mathrm{S}_{\mathrm{pO}_{2}}$ showed no significant variation with IPV or CPT from T0 to T3: from $92 \pm 2 \%$ to $93 \pm 2 \%(P=.051)$ with IPV, and from $93 \pm 2 \%$ to $93 \pm 3 \%(P=.56)$ with CPT. There was no significant difference between the treatments $(P=.34)$.

- With both IPV and CPT, heart rate significantly decreased from T0 to T3: from $86 \pm 11$ beats/min to $82 \pm 11$ beats $/ \mathrm{min}$ with IPV $(P=.002)$, and from $87 \pm 10$ beats $/ \mathrm{min}$ to $83 \pm 11$ beats $/ \min (P=.038)$ with CPT. There was no significant difference between the treatments $(P=.82)$.

- Respiratory rate significantly decreased with IPV, from $21 \pm 4$ breaths/min at $\mathrm{T} 0$ to $19 \pm 4$ breaths $/ \mathrm{min}$ at T3 $(P=.02)$, whereas it did not significantly change with CPT (21 \pm 4 breaths/min at T0 versus $21 \pm 5$ breaths/ $\min$ at T3, $P=.58$ ). There was a significant difference between the treatments $(P=.047)$.

Adverse effects (dry throat, nausea, and/or fatigue) occurred in $27 \%$ of the patients with both IPV and CPT, but the adverse effects were not serious enough to require discontinuation of treatment. 


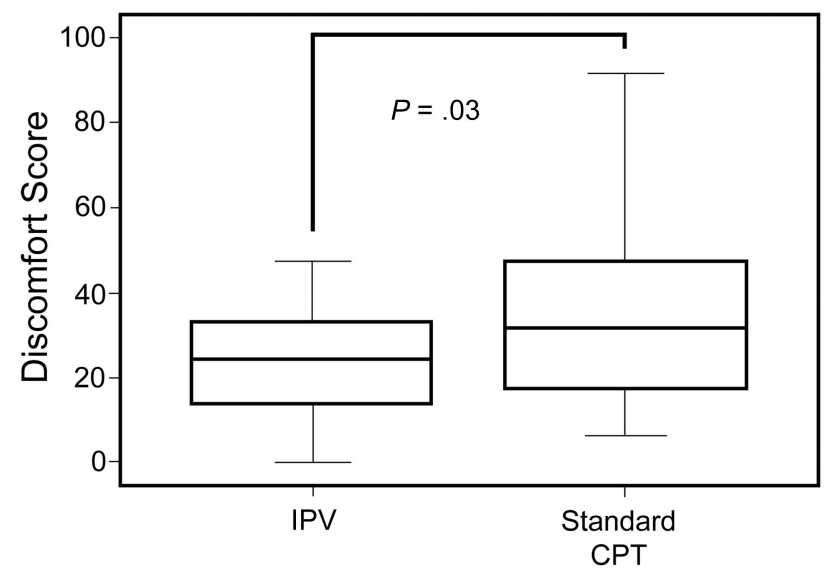

Fig. 1. Median, SD, and IQR of patient discomfort after 30 min of intrapulmonary percussive ventilation versus standard chest physical therapy.

\section{Collected Sputum}

With IPV and CPT, $29 \%$ of patients produced $<20 \mathrm{~mL}$, $41 \%$ produced $20-40 \mathrm{~mL}, 16 \%$ produced $40-60 \mathrm{~mL}$, and only $14 \%$ produced $>60 \mathrm{~mL}$ of sputum at T3. At T3 there were no significant differences between the groups in sputum volume, wet weight, or dry weight (see Table 2).

\section{Dyspnea}

Dyspnea did not worsen with either treatment. IPV significantly improved dyspnea, from $35 \pm 29 \%$ at T0 to $23 \pm 20 \%$ at T3 $(P=.004)$, but CPT did not $(33 \pm 27 \%$ vs $27 \pm 26 \%, P=.09)$. However, there was no significant difference between the groups $(P=.35)$.

\section{Sensation of Phlegm Encumbrance}

Sensation of phlegm encumbrance significantly improved from T0 to T3 in both groups: from $47 \pm 35 \%$ to $27 \pm 32 \%$ with IPV $(P=.001)$, and from $48 \pm 1 \%$ to $37 \pm 35 \%$ with CPT $(P=.03)$. There was no significant difference between the groups $(P=.48)$.

\section{Discomfort}

Post-treatment mean IPV-induced discomfort was lower: $23 \pm 17 \%$ with IPV, versus $40 \pm 27 \%$ with CPT $(P=.03)$, though there was high variability in these measurements (Fig. 1).

\section{Discussion}

In stable adults with bronchiectasis, IPV and CPT had a similar safety profile and physiological and efficacy re- sponse, but IPV had less discomfort. Previous studies have found IPV safe, well tolerated, and effective in various hypersecretive diseases, ${ }^{9}, 10,13,16,21$ but to our knowledge this is the first study of IPV in patients with bronchiectasis. Tsurata et $\mathrm{al}^{15}$ and Van Ginderdeuren et $\mathrm{a}^{22}$ found no significant changes of heart rate after IPV in 2 different trials with obese and CF patients. Our study confirms IPV's cardiovascular safety in patients with bronchiectasis. Similar to the study by Van Ginderdeuren et al, ${ }^{22}$ we observed no change in $\mathrm{S}_{\mathrm{pO}_{2}}$.

In 2 physiological studies with animals, Banzett et $\mathrm{al}^{23}$ and Bohn et al ${ }^{24}$ investigated the effects of IPV on respiratory control. Their data suggest that the rhythmic variations of pressure in the airways produced by high-frequency percussions can induce a bradypnea reflex that originates from mechanoreceptors and from rhythmic vibrations of the rib cage and intercostal muscles, and acts on the respiratory centers. In patients with COPD exacerbation treated with IPV, Vargas et al ${ }^{13}$ observed respiratoryrate reduction similar to what we found in our patients.

As in other studies, ${ }^{9,15}$ short-term IPV caused no major adverse effects: we observed dry throat, nausea, and fatigue, which are probably related to the pressurization of air into the mouth and airways. We did not use humidification during IPV, and it is reasonable to suppose that humidification could reduce the incidence of these adverse effects.

Van Ginderdeuren et al ${ }^{22}$ measured dyspnea with IPV combined with autogenic drainage in 20 stable CF patients and found no significant changes after $15 \mathrm{~min}$ of IPV. We found significant dyspnea improvement after IPV, and we speculate that this could be from a decrease in airways resistance following expectoration. That we found reduced perception of phlegm encumbrance with both IPV and CPT supports that hypothesis.

We found less discomfort with IPV than with CPT. This effect was similar to the one reported by Marks et $\mathrm{al}^{21}$ in $\mathrm{CF}$ patients. Conversely, Varekojis et $\mathrm{al}^{25}$ found was no significant difference in comfort between IPV, high-frequency chest-wall compression, and $\mathrm{CPT}$ in pediatric $\mathrm{CF}$ patients. Our finding might be explained by the discomfort caused by frequent position changes, or by the fact that the patient was in the lateral or prone position during CPT.

IPV was as effective as CPT in terms of sputum volume and weight, which agrees with the findings of Natale et al ${ }^{9}$ in CF patients treated with IPV, aerosol therapy, and CPT. Furthermore, in $24 \mathrm{CF}$ patients Varekojis et $\mathrm{al}^{25}$ found wet sputum weight significantly higher with IPV than with either high-frequency chest-wall compression or CPT.

\section{Limitations}

Our test of IPV's effectiveness was short-term, so we cannot conclude that longer or repeated application of IPV 


\section{Short-Term Intrapulmonary Percussive Ventilation in Patients With Bronchiectasis}

would further improve outcomes. Also, we chose sputum volume as a primary outcome, but we know that several factors influence sputum volume, including rheological characteristic of the sputum, and swallowing. We are also aware that there is some difficulty in finding proper outcome measures in studies of bronchial hygiene techniques.

\section{Conclusions}

Short-term IPV and CPT are similarly safe and effective in patients with bronchiectasis and productive cough, and IPV was associated with less discomfort. We recommend studies on IPV's cost-effectiveness before general clinical application of IPV. However, as a practical clinical implication, our study suggests that, in a hospital setting, IPV is safe in patients with bronchiectasis, and may be especially useful with patients intolerant of CPT because they are unable to maintain lateral or prone position or develop bronchospasm or discomfort during manually assisted maneuvers. ${ }^{4}$

\section{ACKNOWLEDGMENT}

We thank Alessandro Bettini for editing assistance.

\section{REFERENCES}

1. Garrod R, Lasserson T. Role of physiotherapy in the management in chronic lung disease: an overview of systemic reviews. Respir Med 2007;101(10):2429-2436

2. Ilowite J, Spiegler P, Chawla S. Bronchiectasis: new findings in the pathogenesis and treatment of this disease. Curr Opin Infect Dis 2008;21(2):163-167.

3. O'Donnel AE. Bronchiectasis. Chest 2008;134(4):815-823

4. McCool FD, Rosen MJ. Nonpharmacologic airway clearance therapies. ACCP Evidence-Based Clinical Practice Guidelines. Chest 2006; 129(1):250-259.

5. Mutalithas K, Watkin G, Willing B, Wardlaw A, Pavord ID, Birring SS. Improvement in health status following bronchopulmonary hygiene physical therapy in patients with bronchiectasis. Respir Med 2008;102(8):1140-1144.

6. Patterson JE, Bradley JM, Elborn JS. Airway clearance in bronchiectasis: a randomized crossover trial of active cycle of breathing techniques (incorporating Postural drainage and vibration) versus test of incremental respiratory endurance. Chronic Respir Dis 2004; 1(3): 127-130.

7. Bott J, Blumenthal S, Buxton M, Ellum S, Falconer C, Garrod R, et al.;British Thoracic Society Physiotherapy Guideline Development Group. Guidelines for the physiotherapy management of the adult, medical, spontaneously breathing patient. Thorax 2009;64(1):1-51.

8. White G. Equipment theory for respiratory care. Spokane, WA: Delmar; 1996:(12):229-232.

9. Natale JE, Pfeifle J, Homnick DN. Comparison of intrapulmonary percussive ventilation and chest physiotherapy: a pilot study in patients with cystic fibrosis. Chest 1994;105(6):1789-1793.
10. Homnick DN, White F, De Castro C. Comparison of effects of an intrapulmonary percussive ventilator to standard chest physiotherapy and aerosols in the treatment of cystic fibrosis. Pediatr Pulmonol 1995;20(1):50-55.

11. Toussaint M, De Win H, Steens M, Soudon P. Effect of intrapulmonary percussive ventilation on mucus clearance in Duchenne muscular dystrophy patients; a preliminary report. Respir Care 2003; 48(10):940-947.

12. Deakins K, Chatburn RL. In comparison of intrapulmonary percussive ventilation and conventional chest for the physiotherapy treatment of atelectasis in the pediatric patient. Respir Care 2002;7(10): $1162-1167$.

13. Vargas F, Bui HN, Boyer A, Salmi LR, Gbikpi-Benissan G, Guenard $\mathrm{H}$, et al. Intrapulmonary percussive ventilation in acute exacerbation of COPD Patients with mild respiratory acidosis: a randomized controlled trial. Crit Care 2005;9(4):382-389.

14. Antonaglia V, Lucangelo U, Zin WA, Peratoner A, De Simoni L, Capitanio G, et al. Intrapulmonary percussive ventilation in tracheostomized Patients with acute exacerbation of chronic obstructive disease using a helmet. Crit Care Med 2006;34(12):2940-2945.

15. Tsuruta R, Kasaoka S, Okabayashi K, Maekawa T. Efficacy and safety of intrapulmonary percussive ventilation superimposed on conventional ventilation in obese patients with compression atelectasis. J Crit Care 2006;21(4):328-332.

16. Clini EM, Antoni FD, Vitacca M, Crisafulli E, Paneroni M, ChezziSilva $\mathrm{S}$, et al. Intrapulmonary percussive ventilation in tracheostomized patients: a randomized controlled study. Intensive Care Med 2006;32(12):1994-2001.

17. Stiller K, Jenkins S, Grant A, Geake T, Taylor J, Hall B. Acute lobar atelectasis: a comparison of five regimens physiotherapy. Physiother Theory Pract 1996;12:197-209.

18. AARC Clinical Practice Guideline: Postural drainage therapy. Respir Care 1991;36(12):1418-1426.

19. Aitken RC. Measurement of feelings using visual analogue scales. Proc Soc Med 1969;62(10):989-993.

20. Arens R, Gozal D, Omlin KG, Vega J, Boyd KP, Keens TG, et al. Comparison of high frequency chest compression and conventional chest physiotherapy in hospitalized patients with cystic fibrosis. Am J Respir Crit Care Med 1994;150(4):1154-1157.

21. Marks JH, Hare KS, Sauders RA, Homnick DN. Pulmonary function and sputum production in patients with cystic fibrosis: a pilot study comparing the PercussiveTech HF device and standard chest physiotherapy. Chest 2004;125(4):1507-1511.

22. Van Ginderdeuren F, Verbanck S, Van Cauwelaert K, Vanlaethem S, Schuermans D, Vincken W, et al. Chest physiotherapy in cystic fibrosis: short-term effects of autogenic drainage preceded by wet inhalation of saline versus autogenic drainage preceded by intrapulmonary percussive ventilation with saline. Respiration 2008;76(2): 175-180.

23. Banzett R, Lehr J, Geoffrey B. High frequency ventilation lengthens expiration in anesthetized dogs. J Appl Physiol 1983;55:329-334.

24. Bohn DJ, Miyasaka K, Marchak BE, Thompson WK, Froese AB, Bryan AC. Ventilation by high-frequency oscillation. J Appl Physiol 1980;48(4):710-716.

25. Varekojis SM, Douce FH, Flucke RL, Filbrun DA, Tice JS, McCoy $\mathrm{KS}$, et al. A comparison of the therapeutic effectiveness of and preference for postural drainage and percussion, intrapulmonary percussive ventilation, and high-frequency chest compression in hospitalized cystic fibrosis patients. Respir Care 2003;48(1):20-21. 